\title{
A Critical Analysis of Gulma Aimed at Practical Management
}

\author{
Review Article
}

\section{Yarlagadda Nadendra Kumar ${ }^{1 *}$, Anumarlapudi Jayaram ${ }^{1}$}

1. Professor, Department of P.G.Studies,

L.K.R. Ayurveda Mahavidyalaya, Gadhinglaj, Dist.Kolahapur, Maharashtra.

\begin{abstract}
One of the diseases that have become enigmatic over a period of time, subsequently becoming one of academic interest and discussion is Gulma. Various theories were put forward regarding its pathology and modern equivalents like Phantom tumor, Gaseous tumor which are themselves non-specific in nature, none having a practical approach in daily practice. Sites of Gulma such as Hridaya. Nabhi, Parsva, Vasthi are also the sites of Diverticular disease. Diverticulum and its later manifestation as Diverticulosis and Diverticulitis are similar to Gulma and the diffenrent types like Vataja, Pittaja, Kaphaja and Sannipathaja Gulma as explained by our Acharyas. This disease is compared to Diverticular disease with justifications, so that physicians can try medical care, which, hitherto is limited purely as academic subject, and also paves the way for further analysis into the classification of Gulma and its manifestation as compared to Diverticulitis, so that Ayurvedic treatment modalities can be applied accordingly, which requires extensive clinical study.
\end{abstract}

Keywords: Gulma, Diverticulitis, Diverticulosis, Phantom Tumor, Gaseous Tumor, Grandhivat.

\section{Introduction}

In Ayurveda, during the course of time from its inception, many drugs and diseases became enigmatic. Some drugs are controversial and some are not identified at all. Similarly in the diagnosis part, some diseases are not identified or interpreted differently by different physicians. This may be due to the fact, that this system was propagated by Guru Shishya Parampara and lack of documented explanation. The disciples tend to understand the same explanation differently, as is natural. As the time passed over the years and particularly in the reign of Ashoka, many surgical diseases could not be operated upon and the practice of handing down the practical knowledge suffered a major setback, resulting in vagueness of treatment, particularly in surgery. Ultimately even the diseases became enigmatic as practical demonstration of disease and its treatment was not possible. Over the period some of the diseases became only of academic interest because of this vagueness and one of the diseases is Gulma.

This disease is interpreted by different authors differently, the most common term being used is Phantom tumor, which in itself a vague term, which can be understood and diagnosed in a patient differently by different physicians. At present, this disease has become one of academic interest and the treatment aspect is not followed practically due to the above reasons. Our ancestors must have meant a real disease

\footnotetext{
*Corresponding Author:

Yarlagadda Narendra Kumar

Professor,

L.K.R. Ayurveda Mahavidyalaya,

Gadhinglaj, Dist.Kolahapur,

Maharashtra.

Email id: ynkumar@yahoo.co.in
}

while using the term Gulma, particularly when even surgical treatment is explained by Sushrutha. It is time that we try to find out what exactly they meant and apply the principles for the betterment of health care, instead of keeping it as academic discussing point.

In this article an attempt is made to analytically correlate the disease with present day diagnosed, and confirmed disease of Diverticulosis broadly, so that Ayurvedic principles can be applied to this disease at least medically, if not surgical procedures. It will also pave the way to understand the dosha types and correlate accordingly, to pursue the treatment principles.

\section{Aim}

To clear the ambiguity of understanding the disease Gulma.

\section{Objectives}

\section{Disease}

To analytically compare Gulma with Diverticular

To pave the way for Ayurvedic treatment in Diverticulosis and Diverticulitis

To assign a single disease in all physicians' perspective of the disease Gulma

To pave way for further studies to understand the disease with respect to its subdivisions.

\section{Review of Literature Gulma}

Meaning: Apart from other meanings the one relevant to medicine are a cluster or clump of trees, thicket, bush shrub; a chronic enlargement of the spleen or any glandular enlargement in the abdomen ( as that of the mesenteric gland \&c) (1)

A clump or cluster of trees, a thicket, wood, bush 3. The spleen 4. A chronic enlargement of the spleen. (2) 


\section{Aetiopathology}

Definition and number of Gulmas:-The fundamental principles of the body, deranged and aggravated by their respective or specific exciting causes and factors tend to accumulate in the cavity of the abdomen (Koshtha) and help the formations of ball like tumors or Gulmas (internal tumors inclusive of those known as the phantom tumours) somewhere inside the body lying between the extreme confine of the regions of the heart and of the bladder (Vasti). The Gulma is of five kinds and found to be round or spheroid in shape and may be either fixed or mobile (Lit. shifting) in their character and subject to variations in their mass and size.

\section{Localisation and nomenclature}

They have five locations inside the abdominal cavity Viz., the two sides, the region of the heart, the bladder (Vasti) and the region of the umbilicus). The Gulmas are so named because their root or base cannot be exactly localized as well as their cause cannot be exactly ascertained owing to the fact of their having their origin in the aggravated condition of the local bodily Vayu or because of their being but a agglomeration of the deranged bodily Doshas in the affected locality and the shrub-like large converse outline of the surface (Gulma-shrub). Since a Gulma, like a bubble of water, is a self-contained agglomeration of the deranged bodily Doshas and freely moves about in the cavity of its growth, it is not marked by the advent of any suppurative process in its mass or body. The Gulmas are the products of either the several or concerted actions of three Doshas, while in females, a separate class of tumours intimately connected with the deranged or vitiated condition of the blood (menstrual fluid etc.) is also recognized.

Premonitory Symptoms:-A sense of lassitude, dullness of appetite, pain and rumbling in the intestines, suppression of stool, urine and flatus, incapacity to take food to the full, aversion to food, and an upward coursing of the internal Vayu are the indications which may be set down as the premonitory symptoms of Gulma.

Specific Symptoms:- Pain (Sula) in the region of the heart and the belly (Kukshi), dryness of the throat and of the mouth, suppression of Vayu (flatus), irregularity of digestion and all other symptoms which specifically indicate the deranged condition of the bodily Vayu are the characteristics of the Vataja Gulma. Fever, perspiration, defective digestion, burning sensation, thirst, redness of the body (Anga-raga), bitter taste in the mouth and all other specific symptoms of the deranged Pitta mark the Pittaja type of the disease. A sensation of wetness all over the body, an aversion to food, lassitude, vomiting, water brash, sweet taste in the mouth and all other specific indications of the deranged Kapha are exhibited in the Kaphaja type of the disease. The Tridoshaja type exhibits the symptoms specifically belonging to each of the preceding ones and should be regarded as incurable. (3)

Dry, blackish or red, vascular, round like a cotton thread ball in the body is called as gulma, which is of 7 types due to single, dual and involvement of all doshas. In females an additional one is caused due to raktha.
A person who is emaciated due to fever, vomiting, diarrhea or such other diseases or due to excessive panchakarma; indulges in eating vata causing foods; if one drinks cold water when he is hungry, swims immediately after eating food and such other strenuous exercises, induces vomiting by force even when there is no nausea, containing flatus, faeces and urine when they are about to get naturally excreted, undergoes emesis and purgation therapies without undergoing oil and sudation therapies, and after undergoing such therapies intake of food that takes a long time to get digested and liquid diets, results in vitiation of doshas, effects upper and lower Gastrointestinal tract causes pain finally resulting in Gulma of either of the doshas or in combination of two or all the three, and on palpation gives an impression of Granthi.(4)

Due to unhealthy foods and habits Vitiated doshas cause 5 types of Gulma in the abdomen in the shape of Granthi. It occurs between cardiac region and umbilical regions which is not constant resulting increase or decrease in size and can be mobile or immobile (5)

Anorexia, dysuria, constipation, borborygmi, flatulence, upward movement of vata are common symptoms of gulma.(6)

\section{Differentiating Diagnosis of Gulma and Vidradhi}

It may be asked, how is it that Gulma though caused by, and involving the co-operation of the same deranged Doshas as an internal abscess, does not suppurate, while the latter (Vidradhi) does run into suppuration.

The answer is that a Gulma, though caused by the same deranged Doshas as a Vidradhi, does not resort to any deranged organic matter such as flesh, blood etc., while, on the contrary, in a case of Vidradhi, the deranged flesh and blood of a locality are in themselves transformed into an abscess. A Gulma is like a water bubble floating and moving about within a cavity of the body etc., without any fixed root of its own. Hence it is that a Gulma does not suppurate at all. Suppuration sets in an abscess only because it largely contains flesh and blood unlike a Gulma, which is not formed of any such organic matter and depends only on the aggravated Doshas giving birth to it. Hence, a Gulma does not suppurate at all.(7)

\section{Treatment}

On suffering from Vatika gulma should be uncted first and then treated with timely application of oily purgation, non-unctuous, unctuous enemas.

The patient of paittika gulma should be uncted with kakolyadi ghritha, purgated with sweet formulations and treated with non-unctuous enema.

The patient with kaphaja gulma should be uncted with pippalyadi ghritha, purgated with drastic drugs and treated with non-unctuous enema with similar drugs. (8)

While advising treatment similar to other authors, Vagbhata mentions surgical excision.

A patient of kaphaja gulma should be subjected to unctuous and sudation therapies and when the gulma has reduced or collapsed, ghati yantra should be applied 
as mentioned in yantravidya chapter, ( burn grass inside the ghati or pot and when hot remove the burning ashes and invert the pots opening on gulma area by which the collapsed gulma gets sucked into the pot due to vacuum created in the pot when it cools down), which should be held (by samdamshana yantra), covered with a cloth and excised with either of shastras such as vimarga, ajapada or aadarsa taking care not to injure the intestines (other healthy part) and heart. (9)

\section{Diverticulosis}

Diverticulosis Coli - Diverticula are the outpouchings or herniation of the mucosa and submucosa of the colon through the muscle wall. Diverticular disease, as it is commonly known a, is rare under 30 years of age and is seen more commonly as the age advances. Multiple diverticula of the colon are very common in the western societies, probably due to lowfiber diet but is seen much less frequently in tropical countries and Japan. Diverticulosis is often asymptomatic and detected incidentally at autopsy finding, however a proportion of patient have symptoms such as abdominal pain, distention, constipation, and intermittent bleeding.

The etiological role of following 2 factors is accepted in the pathogenesis of diverticular disease.

Increased intraluminal pressure such as due to low fiber content of diet causes hyperactive peristalsis and there by sequestration of mucosa and sub mucosa.

Muscular weakness of colonic wall at the junction of muscular and submucosa (10)

\section{Diverticulosis}

Diverticula are acquired and are most common in the sigmoid and desending colon of the middle aged people. Asymptomatic diverticula are present in over $50 \%$ of people above 70 years of age. Symptomatic diverticular disease supervenes in 10 to $25 \%$ of cases while complicated diverticulosis (acute diverticulitis, pericolic abcess, bleeding, perforation or stricture) is un common.

\section{Pathophysiology}

A life-long refined diet with a relative deficency of fibre is widely thought to be responsible and the condition is rare in populations with a high dietary fibre intake, such as in Asia, where it more often affects the right side of colon. It is postulated that small-volume stools require high intraolonic pressure for propulsion and this leads to herniation of mucosa between the taeniae coli. Diverticula consists of protrusions of mucosa covered by peritonium. There is commonly hypertrophy of circular muscle coat. Inflammation is thought to result from impaction of diverticula with faecoliths. This may resolve spontaneously or progress to cause haemorrhage, perforation,local abcess formation, fistula and peritonitis. Repeated attacks of inflammation leads to thickening of bowel wall, narrowing of lumen and eventual obstruction.

\section{Clinical features}

Symptoms are usually the result of associated constipation or spasm. Colicky pain is suprapubic or felt in the left iliac fossa. The sigmoid colon may be palpable and in attacks of diverticulitis, there is local tenderness, guarding, rigidity (left-sided appendicitis) and sometimes a palpable mass. During these episodes, there may be diarrhea, rectal bleeding or fever. (11)

Types

Diverticulosis is the initial primary stage of the disease, where in there is hypertrophy, muscular incoordination leading to increased segmentation and increased intraluminal pressure. At this stage they are asymptomatic, but often get severe spasmodic pain due to colonic segmentation called painful diverticular disease.

Diverticulitis is the second stage due to inflammation of one or more diverticula with pericolitis. It presents with persistent pain in left iliac fossa, fever, loose stool, recurrent constipation and tenderness in left iliac fossa, palpable and thickened sigmoid colon. $\mathrm{P} / \mathrm{R}$ may reveal mass. Diverticulitis can be uncomplicated diverticulitis presenting with pain and spasm over left iliac fossa, fever. Recurrent attacks need sigmoid colectomy. It can be done electively through laparoscopy. Complicated diverticulitis present with hemorrhage, abscess, fistula formation, perforation, peritonitis and obstruction due to stenosis. Vesicocolic fistula presents with pneumonia. Diverticula associated colitis (DAC) presents with tenesmus, diarrhea and hematochezia. DAC is a distinct clinical entity with segmental colitis

Only $15 \%$ of patients with diverticulosis develop diverticulitis. $75 \%$ of patients with diverticulitis have uncomplicated course with features of only diverticulitis. $25 \%$ of patients with diverticulitis develop complications like abscess, perforation, stenosis and fistula. Abscess can be commonly pericolic and pelvic, rarely in buttock and ischiorectal fossa.

Features of diverticulosis are fullness of abdomen, bloating, flatulence (12)

A diverticulum is a blind outpouching protruding through the muscle wall in any part of the gut and communicating with the lumen of the gut. Meckel's diverticulum, is a congenital diverticulum and all other diverticulum are usually acquired and develop in the people over 60 years old. The majority arise in sigmoid and descending colon. Diverticula are much less common in small intestine. Most of the small intestinal diverticula are in the duodenum and might be a consequence of healed peptic ulcer disease.

Pathogenesis

Diverticula of the colon develop during adult life when the increased intraluminal pressure in the colonic wall. As the outer longitudinal muscular coat in the colon is not complete but forms the taenia coli, the site of entry of a blood vessel through the inner circular muscle coat is a weak spot for herniation. The lack of bulk and fiber in the diet increases peristaltic activity in the intraluminal pressure in the colon. Contraction of the ridges of circular muscle often present in patients with diverticulosis could close off segments of the 
colon and increase the pressure in the closed segments, forcing out a diverticulum from the weakened region between the ridges.

\section{Lesions}

Colonic diverticula are often numerous and the condition is known as diverticulosis. The diverticula are usually $0.5-1 \mathrm{~cm}$ in size and project beyond the wall of the colon adjacent to the taeniae coli. Often, the diverticula project into the appendices epiploicae or into pericolic fat and are not visible from the outer surface of the colon. When a diverticulum is visible, it is often blue because of the fecal matter it contains. Most colonic diverticula are flask-shaped, with a narrow neck where the diverticulum passes through the muscle of the colonic wall and a bulbous body. (13)

\section{Diverticula}

An intestinal diverticulum means herniation of the bowel through its wall. It may be either true or false. A true diverticulum contains all the layers of the bowel in its wall e.g., congenital Meckel's diverticulum. False diverticula are acquired conditions in which herniation of the wall of the bowel and the wall consists of mucosal and serosal layers. They occur in the small and large intestines but are common in the latter position.

\section{Acquired diverticula}

The common situations for the formation of diverticula are the esophagus, duodenum, small intestine and colon. These are actually false diverticula, though some may have muscle fibers in their walls.

\section{Duodenal diverticulum}

This may be recognized in two forms, namely; primary and secondary. The primary one commonly arises from the second part of duodenum and rarely from the firs or third parts. It is seen in the inner and posterior aspects of the bowel along the line of entrance of the vessels, which weaken the wall and there is herniation of the mucosa through a gap in the muscular coat. It may be single or multiple and occur in middle or late life. In about $70 \%$ of cases the diverticula are in close relation to ampulla of Vater. Symptoms of dyspepsia may sometimes arise from pressure of the diverticula. Secondary diverticulum arises as a sequel of duodenal ulcer and therefore, it occurs as a sequel of duodenum. It results from bulging of one or both sides of healed scar causing traction of the wall.(14)

\section{Discussion}

When we go through the above literature of Gulma and Diverticulosis /Diverticulitis we noted that

The definition or literary meaning of Gulma is Shrub, which is a small bushy plant with branches. When we look at the barium enema in case of Diverticulosis, we find the image as hacksaw if the diverticula are limited to one side and like a small plant with branches when involving the circumference of the colon.
The places of occurrence also are similar.

At the cardiac or epigastric region - esophageal diverticula such as Zenker's and rarely occurring Gastric diverticulum.

Meckel's diverticulum is an outpouching or bulge in the lower part of the small intestine. The bulge is congenital (present at birth) and is a leftover of the umbilical cord and similar to what is explained

Diverticulum occurs in intestines on both sides of abdomen while it is more common on left side i.e., in the colon.

Bladder diverticulum occurs in patients with $\mathrm{BPH}$ and urethral stricture. rarely

Uterine Diverticulum is known to occur, though

This article is restricted to only the Diverticular disease excluding the Uterine diverticulum.

Acquired diverticulum in the initial stages will appear as a bulge, only when there is excessive pressure, like in case of constipation and when the pressure is normal it will not be seen or it appears when there is internal pressure over the weakened wall and disappears when the pressure is relieved.

When the diverticulum develops in small intestines and is persistent due to chronicity, it moves along with the segments during peristalsis, while in the sigmoid they are more or less stable.

There will not be any pathological changes in case of simple diverticulum as far as its wall is concerned. The diverticular tissue if excised and examined, will not reveal any pathology. It is diverticulum only with respect to the surrounding tissue in vivo. Only in cases of infection/diverticulitis inflammatory/infection changes are seen. This substantiates that Gulma doesn't involve any Dhatu and hence doesn't suppurate (unless there are supervening causes). Still it is a part of the underlying tissue as in case of a water bubble which cannot be called as water itself, as it doesn't have independent entity. Diverticulum appears when pressure is exerted and disappears when it is relieved in initial stages. No tissue can be called as diverticulum separately from its base.

Signs and symptoms of Diverticulosis and Gulma coincide with gastrointestinal symptoms. Though mentioned, Gulma at different regions is not explained separately.

Bladder diverticulum or Vasthi Gulma is not given importance except its mention in any of the classics.

In cases of infection and obstruction, the symptoms vary from acute diverticulitis to chronic diverticulitis and diverticular abscess, corresponding to signs and symptoms of Vataja, Pittaja and Kaphaja Gulma.

Usually complications of simple diverticulum arise due to constipation and care is taken to have the regular bowel movements, particularly in initial stages this helps a lot in preventing progress of the disease process and complications thereon. Ayurveda addresses this disease with treatment aimed at improving digestion and regulate bowel movements.

Even surgical excision advised in Ayurveda indicates that it can't be visualized per se. A vacuum has to be created by a heated pot and the tissue which is 
sucked has to be excised. The tissue obviously will be the one which is weak and expands when internal pressure increases in a person, as in case of constipated bowels.

Suppuration occurs as a complication in case of chronic diverticulitis which is recognized in Ayurveda also.

A phantom tumor as advocated by many cannot be correct as it is only a gaseous expansion and need not be surgically excised as the gas moves around and excision of any specific portion will not cure the problem, referring to it as gaseous tumor by some invokes the same logical explanation. Further if the Acharyas felt that it is a tumor, whatever type it is, they would have included under Arbuda or Granthi. While explaining they described it as Grandhivat - Like Grandhi; and not as Grandhi.

\section{Conclusion}

We can safely come to a conclusion that Gulma mentioned in classics, could have been diverticulosis and is lost its identity during the intervening time after Sushrutha. It is suggested that the Ayurvedic practitioners try out the medications which are mentioned in the classics, mainly to correct the digestive system, the main organ that was given importance in explaining the signs, symptoms and treatment of the disease, though other areas were described as the places of occurrence, such as Vasthi Further, extensive study is recommended to correlate diverticulosis/diverticultis and complications to those of Gulma of various Doshas to apply the treatment principles accurately.

\section{References}

1. Monier Monier Sir -Williams, A Sanskrit English Dictionary- Motilal Banarasidass, Delhi, 1899 Ed. 360p.

2. Vaman Shivaram Apte, The Practical Sanskrit English Dictionary, Motilal Banarsidass, 1965 Ed.409p.
3. Kaviraj Kunjlal Bhishagratna, An English Translation of The Sushrutha Samhitha Volume III, Uttara Tantra XLII /2-9, S L Bhaduri, Kashi Ghose Lane, Calcutta,1916, 246,247p.

4. Vagbhata Ashtanga Hridaya Nidana Sthana11/3137, Vavilla Ramaswami Shastrulu \& Sons, Madras, 1930341,342 p.

5. Krishna Sharma,. Yogaratnakara Gulmanidanam, Tukaram Javaji,1907,Nirnayasagar Press, Mumbai, 273 p.

6. Basavaraju, Basavarajeeyam 29/5, Vavilla Ramaswamy Shastrulu \& Son, Madras , 1948;769,770p.

7. Kaviraj Kunjlal Bhishagratna, An English Translation of The Sushrutha Samhitha Volume II,Nidana Sthana 9/23-24, Kaviraj Kunjlal Bhishagratna No.10 Kashi Ghose Lane Calcutta,1911, 65,66p.

8. Sharma P.V., Sushrutha Samhitna Vol. III, Uttara Tantra Ch.XLII/16-18, Chowkamba Viswabharathi, Varanasi, IEd.,2001. 423-424p.

9. Vagbhata Ashtanga Hridaya Chikitsa Sthana14/8486, Vavilla Ramaswamisathrulu \& Sons, Madras, 1930. 298.299p.

10. Harsh Mohan, Text Book Of Pathology, Jaypee Brothers, New Delhi, $4^{\text {th }}$ Ed 2000,557, 558p.

11. Davidson, Principles and Practice of Medicine, Churchil Livinstone Elaevier, China,22 ${ }^{\text {nd }}$ Ed.,2014, 916, 917 p.

12. Sri Ram Bhat, SRB's Manual of Surgery, Jaypee Brothers Medical Publishers (P) Ltd., New Delhi, $4^{\text {th }}$ Ed. 2013, 951-053p.

13. William Boyd, Text Book of Pathology Vol II, Wolters Kluwer (India) Pvt. Ltd., New Delhi, $10^{\text {th }}$ Ed., 2013, 958-960p.

14. Dey N C \& Dey T K, A Text Book of Pathology, New Central Book Agency (P) Ltd., Calcutta, $15^{\text {th }}$ Ed., 2000, 18.25, 18.26p. 